\title{
Laparoscopic surgery: It is no necessary to change ventilator mode to improve ventilation conditions; a controlled trial
}

\author{
Khalil Mounir, Tarik Lamkinsi, Hamza Hamzaoui, Smail Issa, Mustapha Bensghir, and Salim Jaafar Laalaoui
}

\begin{abstract}
Hôpital Militaire d'Instruction Mohammed V Rabat, Sidi Mohammed Ben Abdellah Unversity, Fès, Morocco
\end{abstract}
Backgrounds/Aims: The main objective of this study is to compare the ventilatory effects of AFVC and PC modes with the VC mode in laparoscopic surgery of the gall bladder. Methods: Thirty-five patients programmed for laparoscopic cholecystectomy were included. Four times were defined for all patients. The parameters studied were recorded ten minutes after anesthetic induction; and this is the time T1. The time T2 fits to $10 \mathrm{~min}$ after induction of pneumoperitoneum. Then, the ventilator mode was changed from VC mode to AFVC mode. Ten minutes later, the variables were scored; it was the time T3. The ventilator mode was then changed to a PC mode. The set pressure was adjusted in order to obtain the same Vt as at the time T2. The time T4 was 10 minutes after switching to PC mode. Results: The Vte were increased, compared to time T2, during the AFVC and PC modes. The induction of pneumoperitoneum with $\mathrm{CO}_{2}$ induced a rise of $\mathrm{P}_{\mathrm{ET}} \mathrm{CO}_{2}$ between $\mathrm{T} 1$ and $\mathrm{T} 2$. These had been accompanied by a significant rise in airway pressures. The change from VC mode to AFVC mode resulted in lower Prpeak and Prtray elevation without impacting dynamic compliance. Conclusions: AFVC mode appears safe for patients in laparoscopic surgery. Its use, compared with VC, is associated with a decrease in Prpeak without effects on the Cdyn, oxygenation, capnia and hemodynamic parameters. We conclude that is no necessary to change ventlatory modes to improve ventilation conditions in nonobese patients. (Ann Hepatobiliary Pancreat Surg 2019;23:163-167)

Key Words: Pneumoperitoneum; Laparoscopy; Ventilation mode; Dynamic compliance

\section{INTRODUCTION}

Laparoscopic surgery has been performed increasingly since the end of the last century. Indeed, it causes less tissue trauma, reduction in postoperative pain and early recovery and return to usual activity as well. However, this procedure remains risk-free. Cardiopulmonary consequences of laparoscopic surgery are currently well known. ${ }^{1}$ One of the most obvious respiratory effects is the increase in peak pressure (P peak), the reduction of which is due to the change in the respiratory rate (RR), or the tidal volume $(\mathrm{Vt})$ or even the ventilatory mode of a volume mode controlled (VC) to a controlled pressure mode (PC).

The "dual controlled" modes combine the advantages of controlled volume and pressure modes. ${ }^{3,4}$ The AutoFlow $^{\mathrm{TM}}$ mode $(\mathrm{AF})$ of the Dräger Zeus Infinity ventilator is one of these doubly controlled modes. All breathing cy- cles are controlled under pressure with a delivered pressure level which varies from one respiratory cycle to another, so as to guarantee the regulated tidal volume $(\mathrm{Vt})$. The AF uses a feedback loop that regulates inspiratory flow. Dynamic compliance is measured cycle by cycle. This allows the determination of the pressure required for the next cycle by dividing the desired $\mathrm{Vt}$ by this compliance. Changes in inspiratory pressure between cycles are limited to 3 mbar. When the inspiratory pressure reaches the upper limit minus $5 \mathrm{mbar}$, the inspiratory time is extended to within the allowable respiratory rate. ${ }^{5}$ To the best of our knowledge, no controlled studies of auto-flow controlled volume (AFVC) in laparoscopic surgery have been published.

The principal hypothesis was that AFVC mode improve ventilation conditions in laparoscopic surgery for nonobese patients. So, the main objective of this study is to

Received: December 4, 2018; Revised: February 19, 2019; Accepted: February 21, 2019

Corresponding author: Khalil Mounir

Military Hospital Mohammed the V, Rabat 10000, Morocco

Tel: +212-661106216, E-mail: mkhalildoc@gmail.com

Copyright (C) 2019 by The Korean Association of Hepato-Biliary-Pancreatic Surgery

This is an Open Access article distributed under the terms of the Creative Commons Attribution Non-Commercial License (http://creativecommons.org/ licenses/by-nc/4.0) which permits unrestricted non-commercial use, distribution, and reproduction in any medium, provided the original work is properly cited. Annals of Hepato-Biliary-Pancreatic Surgery - pISSN: 2508-5778 - elSSN: 2508-5859 
compare the ventilatory effects of AFVC and PC modes with the $\mathrm{VC}$ mode in laparoscopic surgery of the gall bladder.

\section{MATERIALS AND METHODS}

This is a prospective study wherein patients are controlling themselves. After agreement of the local ethics committee, informed consent was obtained. The study was conducted at the aseptic block of the Military Instruction Hospital Mohammed V in Rabat, Morocco.

Thirty-five patients programmed for laparoscopic cholecystectomy were included. Patients who are ASA III or IV, obese (BMI $>30 \mathrm{~kg} / \mathrm{m}^{2}$ ), asthmatics (stable or unstable), with chronic bronchopneumopathy or left or right heart failure or moderate to severe valvulopathy were not included in the study. Second, patients with intraoperative hemodynamic instability (defined as a systolic blood pressure below $90 \mathrm{mmHg}$ ), intraoperative bleeding (defined by the need for large volumes of crystalloids or transfusion of red blood cells) or who underwent conversion to open surgery were excluded. The anesthetic protocol was standard for all patients. Premedication was performed with $2 \mathrm{mg} / \mathrm{kg}$ of hydroxyzine orally administered the day before surgery. Under a standard monitoring system (non-invasive pressure, electrocardioscope and pulsed oxygen saturation), a peripheral venous pathway allowed intake of $250 \mathrm{ml}$ of $0.9 \%$ saline serum. The induction was made by Fentanyl $4 \mu \mathrm{g} / \mathrm{kg}$, propofol $2 \mathrm{mg} / \mathrm{kg}$ and cisatracurium at $0.15 \mathrm{mg} / \mathrm{kg}$. The curarization was overseen by monitoring the Train Of Four (TOF) at the thumb adductor in all patients. Maintenance of the TOF $>90 \%$ was a continuous objective throughout the operative period, with reinjection of cisatracurium if necessary. The crystalloid was perfused at a basal diet of $10 \mathrm{ml} / \mathrm{kg} / \mathrm{hr}$. After orotracheal intubation, the oxygen-inspired fraction $\left(\mathrm{FiO}_{2}\right)$ was at $50 \%$ in admixture with air. The minute ventilation was adjusted to maintain a $\mathrm{CO}_{2}$ exhalation pressure $\left(\mathrm{P}_{\mathrm{ET}} \mathrm{CO}_{2}\right)$ between 30 and $35 \mathrm{mmHg}$. Intraoperative anesthetic maintenance was performed by Sevoflurane (MAC between $1 \%$ and $2 \%$ ). Pneumoperitoneum with carbon dioxide $\left(\mathrm{CO}_{2}\right)$ was induced in supine position at an intra-abdominal pressure of 12 to $14 \mathrm{mmHg}$.

Patients were initially ventilated in VC mode with an inspiratory/expiratory ratio of $1 / 2$ and no inspiratory tray.
Four times were defined for all patients. The parameters studied were recorded ten minutes after anesthetic induction; and this is the time $T_{1}$. The time $T_{2}$ fits to 10 min after induction of pneumoperitoneum under ventilation in VC mode. After data collection, the ventilator mode was changed from VC mode to AFVC mode. Ten minutes later, the variables were scored; it was the time $\mathrm{T}_{3}$. The ventilator mode was then changed to a PC mode. The set pressure was adjusted in order to obtain the same $\mathrm{Vt}$ as at the time $\mathrm{T}_{2}$. The time $\mathrm{T}_{4}$ was 10 minutes after switching to PC mode.

In addition to the demographic characteristics description (age, gender, weight, height, BMI) ASA, chronic treatments, we have compared the haemodynamics parameters (HR, median arterial pressure and the ratio MAP/HR) respiratory parameters (inspired tidal volume (Vti) and expired tidal volume (Vte), respiratory rate (RR), dynamic compliance $\left(\mathrm{C}_{\mathrm{dyn}}\right.$ given by the ventilator), $\mathrm{SpO} 2, \mathrm{P}_{\mathrm{ET}} \mathrm{CO}_{2}$, peak pressure $\left(\operatorname{Pr}_{\text {peak }}\right)$, tray $\left(\operatorname{Pr}_{\text {tray }}\right)$ and mean $\left(\operatorname{Pr}_{\text {mean }}\right)$ pressures between $T_{2}$ taken as reference and times $T_{3}$ and $T_{4}$.

Data were entered in Microsoft Excel (Microsoft, Redmond, WA, USA) for Windows and statistical analysis was performed using PASW Statistics 18.0 software (IBM, Chicago, IL, USA). Descriptive data were presented as median and interquartile for quantitative variables and as counts and percentages for qualitative variables. Comparisons of the quantitative data were made using the WilcoxonMann-Whitney $U$ test.

We chose a threshold of the first species error $\alpha$ of $5 \%$, which means that any value of $p<0.05$ meant that the difference is statistically significant.

\section{RESULTS}

Of the 35 patients initially included in the study, two were secondarily excluded; the first had a PAS less than $90 \mathrm{mmHg}$ and the second had undergone surgical conversion to open cholecystectomy because of intraabdominal adhesions. Demographic characteristics (age, gender, weight, height, BMI), ASA classes, antecedents and longterm treatments are summarized in Table 1.

The ventilatory and hemodynamic parameters are summarized in Table 2. During the four measurement times, the hemodynamic variables were comparable outside the rise of the MAP between the times $T_{1}$ and $T_{2}$ (88 (79.5-93) 
Table 1. Demographic characteristics and medical history of patients

\begin{tabular}{lc}
\hline \multicolumn{1}{c}{ Paramètres } & Valeurs \\
\hline Age $(\mathrm{ans})$ & $50(38.5-56.50)$ \\
Gender $(\mathrm{M} / \mathrm{F})$ & $12 \%(4) / 88 \%(29)$ \\
Weight $(\mathrm{kg})$ & $75.5(70-84.5)$ \\
Height $(\mathrm{m})$ & $1.64(1.6-1.65)$ \\
Body mass index $\left(\mathrm{kg} / \mathrm{m}^{2}\right)$ & $27.3(25.6-31.5)$ \\
Medical history & \\
HTA & $18.3 \%(6)$ \\
Diabetes & $6.1 \%(2)$ \\
ASA (I/II) & $81.8 \%(27) / 18.6 \%(6)$ \\
preoperative medications & $15.2 \%(5)$ \\
IEC & $3 \%(1)$ \\
$\beta$ blocker & $3 \%(1)$ \\
Aspirine & $0 \%(0)$ \\
Insuline & $0 \%(0)$ \\
Metformine & $6.1 \%(2)$ \\
Sulfamides & \\
Analgesia & $81.8 \%(27)$ \\
Paracetamol & $67.1 \%(22)$ \\
Ketoprofen & $42.7 \%(14)$ \\
Nefopam &
\end{tabular}

Results are in percentage (number) if variable is qualitative; or in median (interquartile Q1-Q3) if variable is quantitative HTA, blood hypertension; Ica, calcium inhibitor; IEC, converting enzyme inhibitor; ARA II, angiotensin II receptor antagonist vs $98(83.5-114) ; p=0.01)$ and the shock index $(1.14$ (1.02-1.5) vs 1.39 (1.1-1.7); $p=0.02)$. The respiratory rate (RR) and the Vti were comparable during all ventilatory periods. However, the Vte were increased, compared to time $\mathrm{T}_{2}$, during the AFVC and PC modes (435 (415-450) and $445(420-460)$ vs 420 (407-442); $p=0.01$ and $p=0.007$ respectively). The induction of pneumoperitoneum with $\mathrm{CO}_{2}$ induced a rise of $\mathrm{P}_{\mathrm{ET}} \mathrm{CO}_{2}$ between $\mathrm{T}_{1}$ and $\mathrm{T}_{2}$ (32 (30-34.5) vs 35 (34-37); $p<0.001)$. These had been accompanied by a significant rise in airway pressures $\left(\operatorname{Pr}_{\text {peak }}\right.$, $\operatorname{Pr}_{\text {tray }}$ and $\left.\operatorname{Pr}_{\text {moy }}\right)$ with a significant drop in dynamic compliance that had gone from 39 (31-53.5) to 33 (29-37) with a $p$-value less than 0.001 .

The change from VC mode to AFVC mode resulted in lower $\operatorname{Pr}_{\text {peak }}$ and $\operatorname{Pr}_{\text {tray }}$ elevation without impacting dynamic compliance. The comparison between the $\mathrm{VC}$ mode and the PC mode showed the decrease of the $\operatorname{Pr}_{\text {peak }}$ and a slight increase of the $\mathrm{Pr}_{\text {tray }}$ without any impact on the dynamic compliance. No patients had intrinsic PEEP greater than $5 \mathrm{~cm} \mathrm{H}_{2} \mathrm{O}$. There was also no effect of ventilatory changes on oxygenation with comparable $\mathrm{SpO}_{2}$ levels at all times.

Table 2. Results of analyzed parameters

\begin{tabular}{|c|c|c|c|c|c|c|c|}
\hline \multirow{2}{*}{ Paramètres } & \multirow{2}{*}{ VC (T1) } & \multirow{2}{*}{ VCpnp (T2) } & \multirow{2}{*}{ AFVC pnp (T3) } & \multirow{2}{*}{ PCpnp (T4) } & \multicolumn{3}{|c|}{$p$} \\
\hline & & & & & $\mathrm{T} 1$ vs $\mathrm{T} 2$ & $\mathrm{~T} 2$ vs $\mathrm{T} 3$ & $\mathrm{~T} 2$ vs $\mathrm{T} 4$ \\
\hline MAP (mmHg) & $88(79.5-93)$ & $98(83.5-114)$ & $93(87.5-105)$ & $94(86-97.5)$ & 0.011 & 0.35 & 0.06 \\
\hline $\operatorname{HR}(/ \min )$ & $75(61-79)$ & $70(56.5-82)$ & $73(58-79)$ & $72(62-79)$ & 0.62 & 0.77 & 0.71 \\
\hline $\mathrm{MAP} / \mathrm{HR}$ & $1.14(1.02-1.5)$ & $1.39(1.1-1.7)$ & $1.44(1.19-1.59)$ & $1.3(1.14-1.53)$ & 0.02 & 0.33 & 0.71 \\
\hline RR (cycle/min) & $12(12-12)$ & $12(12-12)$ & $12(12-12)$ & $12(12-12)$ & 1 & 1 & 1 \\
\hline Vti (ml) & $460(440-475)$ & $460(440-480)$ & $460(450-480)$ & $460(450-480)$ & 0.33 & 0.11 & 0.11 \\
\hline Vte $(\mathrm{ml})$ & $425(405-440)$ & $420(407-442)$ & $435(415-450)$ & $445(420-460)$ & 0.46 & 0.01 & 0.007 \\
\hline $\mathrm{SpO}_{2}(\%)$ & $99(97-100)$ & $99(97-100)$ & $99(97-100)$ & $99(97-100)$ & 1 & 1 & 1 \\
\hline $\mathrm{P}_{\mathrm{ET}} \mathrm{CO}_{2}(\mathrm{mmHg})$ & $32(30-34.5)$ & $35(34-37)$ & $37(34.5-38)$ & $37(35-38)$ & $<0.001$ & 0.11 & 0.07 \\
\hline Rate of flow (L/min) & $5(5-5)$ & $5(5-5)$ & $5(5-5)$ & $5(5-5)$ & 1 & 1 & 1 \\
\hline \multicolumn{8}{|l|}{ Pressure $\left(\mathrm{cm} \mathrm{H}_{2} \mathrm{O}\right)$} \\
\hline Peak & $22(19-24.5)$ & $26(24-28.5)$ & $19(17-21.5)$ & $19(17.5-21)$ & $<0.001$ & $<0.001$ & $<0.001$ \\
\hline Tray & $15(12-17)$ & $17(16-20)$ & $18(17-21)$ & $19(17.75-21)$ & $<0.001$ & $<0.001$ & $<0.001$ \\
\hline Mean & $8(7-8)$ & $8(8-9)$ & $8(7-9)$ & $8(8-9)$ & $<0.001$ & 0.11 & 1 \\
\hline Dynamic compliance & $39(31-53.5)$ & $33(29-37)$ & $33(29.5-35.5)$ & $33(30-40)$ & $<0.001$ & 0.7 & 0.28 \\
\hline $\operatorname{PEEP}\left(\mathrm{cm} \mathrm{H}_{2} \mathrm{O}\right)$ & $2(2-2)$ & $2(2-2)$ & $2(2-2)$ & $2(2-2)$ & 1 & 1 & 1 \\
\hline Pr PNP (mmHg) & - & $12(11.5-12)$ & $12(11-12)$ & $12(11-12)$ & - & 0.18 & 0.18 \\
\hline
\end{tabular}

MAP, mean arterial pressure; $\mathrm{HR}$, heart rate; $\mathrm{RR}$, respiratory rate; $\mathrm{Vti}$, inspired tidal volume; Vte, expiratory tidal volume; $\mathrm{SpO}_{2}$, pulsed saturation of oxygen; $\mathrm{P}_{\mathrm{ET}} \mathrm{CO}_{2}$, tele expiratory pressure in $\mathrm{CO}_{2}$; PEEP, positive end expiratory pressure; Pr PNP, pneumoperitoneum pressure 


\section{DISCUSSION}

Our study demonstrates that during laparoscopy, AFVC and PC slightly decrease the $\operatorname{Pr}_{\text {peak }}$ and discreetly increase the $\mathrm{Pr}_{\text {tray }}$ statistically significantly compared to $\mathrm{VC}$ mode. Dynamic compliance is, however, not improved by changing the ventilatory mode from $\mathrm{VC}$ to AFVC and PC. No respiratory changes are noted outside the elevation of the Vte. In addition, the hemodynamic parameters remain unchanged. The results of this study support data from the literature regarding the effect of peritoneal insufflation on ventilatory parameters. In fact, the induction of pneumoperitoneum is constantly accompanied by an alteration of the compliance of the respiratory system. ${ }^{6,7}$ Reduced ventilatory impact of laparoscopy causes change in respiratory rate $(\mathrm{RR})$, of the current volume $(\mathrm{Vt})$ or ventilatory mode. ${ }^{2} \mathrm{PC}$ mode is now frequently used in the management of patients with elevated $\operatorname{Pr}_{\text {peak }}$ except incomplete knowledge of its hemodynamic effects, ventilation or its complications. ${ }^{8,9}$ The recent study by Sen et al. ${ }^{10}$ confirms that the use of PC mode is associated with lower $\operatorname{Pr}_{\text {peak }}$ both before and after induction of pneumoperitoneum. The AFVC is based on an original and attractive principle; it guarantees $\mathrm{Vt}$ settled respecting the advantages of the PC mode. ${ }^{3,4}$ The theoretical advantages of this mode would, therefore, have a beneficial effect in the reduction of $\operatorname{Pr}_{\text {peak }}$ when these are increased. These data and the lack of knowledge of possible complications have been the basis of our hypothesis that AFVC mode would reduce airway pressures, especially $\mathrm{Pr}_{\text {peak }}$, with an improvement in dynamic compliance. By comparing it to $\mathrm{VC}$ mode, PC ventilation is constantly associated with a decrease in the $\operatorname{Pr}_{\text {peak. }}{ }^{2,8,11-14}$ This effect, although clinically mild, has been statistically significant in our patients. It would be the result of decelerating flow and early dissipation of resistances. ${ }^{14}$ Almost equal $\mathrm{Pr}_{\text {peak }}$ and $\mathrm{Pr}_{\text {tray }}$ observed in our patients in PC mode is linked to the structure of decelerating flow and thus explain the elevated $\operatorname{Pr}_{\text {tray }}$ contrast to studies comparing the VC and PC modes. ${ }^{2,14}$ The main disadvantage of the $\mathrm{PC}$ mode is the variability of the delivered $\mathrm{Vt}^{15}$ Relatively related to $\mathrm{VC}, \mathrm{PC}$ ventilation results in a decrease in $\mathrm{Vt}$ when the compliance of the respiratory system decreases. This can cause undiagnosed atelectasis. ${ }^{16}$ The mode AFVC thus finds all its importance insofar as it ensures the delivery of the set Vt. To our knowledge, no study has evaluated the respiratory effects of AFVC mode in laparoscopic surgery. This gives our study all its originality but on the other hand makes the discussion of the results difficult. Compared to VC mode, VC mode with regulated pressure is associated with lower inspiratory pressures. ${ }^{14,17,18}$ In a randomized controlled trial evaluating AFVC mode in controlled ventilatory ventilation, this mode allowed fewer alarms by reducing inspiratory pressures. ${ }^{5}$ The changes in the $\mathrm{C}_{\mathrm{dyn}}$ were not significant in our patients between the three ventilatory modes. Mang et al. ${ }^{19}$ have demonstrated a change in the distribution of gas in the lungs of patients with acute lung injury when the $\mathrm{C}_{\mathrm{dyn}}$ changes. In iso-volumetric conditions, variations in $\mathrm{C}_{\mathrm{dyn}}$ depended as much on the elastic properties of the respiratory system as on the resistive component of the airways and the intubation tube. The lack of impact of ventilatory changes on hemodynamic parameters reinforces the results found in the literature.,11-13 There has been no clinical impact of changing patterns of pulsed oxygen saturation. This may be related to the selection of patients in our study who did not have risk factors for hypoxemia or desaturation, making the benefit of each of the ventilatory modes difficult to highlight.

This study, however, retains certain limits. Patients are not randomized and their numbers are reduced. The study can not be conducted blind because of the visibility of both the parameters set and the variables analyzed on the screen of the respirator. The short duration of each ventilatory mode is due to insufficient time of surgery. Intra pleural pressure was not measured. Hemodynamic parameters, oxygenation and capnia were non-invasively monitored because of the lack of clinical implication of the weak repercussions of ventilatory modes in literature.

In conclusion, AFVC mode appears safe for patients undergoing laparoscopic surgery in this trial. Its use, compared with $\mathrm{VC}$, is associated with a decrease in $\operatorname{Pr}_{\text {peak }}$ without effects on the $C_{d y n}$, oxygenation, capnia and hemodynamic parameters. Studies on larger scales, on atrisk populations, and the ventilatory impact of the change of the mode such as the obese population are necessary in order to judge its efficiency and its security. In summary, we conclude that it is not necessary to change modes on the ventilator for improving ventilator conditions when proceeding with laparoscopic surgery of the gallbladder in non-obese patients. So, further study on the 
effect of ventilatory mode about obese population appear necessary.

\section{REFERENCES}

1. Sharma KC, Brandstetter RD, Brensilver JM, Jung LD. Cardiopulmonary physiology and pathophysiology as a consequence of laparoscopic surgery. Chest 1996;110:810-815.

2. Balick-Weber CC, Nicolas P, Hedreville-Montout M, Blanchet $\mathrm{P}$, Stéphan F. Respiratory and haemodynamic effects of volumecontrolled vs pressure-controlled ventilation during laparoscopy: a cross-over study with echocardiographic assessment. Br J Anaesth 2007;99:429-435.

3. Branson RD, Davis K Jr. Dual control modes: combining volume and pressure breaths. Respir Care Clin N Am 2001;7:397-408, viii.

4. Campbell RS, Davis BR. Pressure-controlled versus volume-controlled ventilation: does it matter? Respir Care 2002;47:416-424; discussion 424-426.

5. Lasocki S, Labat F, Plantefeve G, Desmard M, Mentec H. A long-term clinical evaluation of autoflow during assist-controlled ventilation: a randomized controlled trial. Anesth Analg 2010; 111:915-921.

6. Feinstein R, Ghouri A. Changes in pulmonary mechanics during laparoscopic cholecystectomy. Anesth Analg 1993;76:S102.

7. Oikkonen M, Tallgren M. Changes in respiratory compliance at laparoscopy: measurements using side stream spirometry. Can J Anaesth 1995;42:495-497.

8. Tuğrul M, Camci E, Karadeniz H, Sentürk M, Pembeci K, Akpir $\mathrm{K}$. Comparison of volume controlled with pressure controlled ventilation during one-lung anaesthesia. Br J Anaesth 1997;79: 306-310.

9. Nadu A, Ekstein P, Szold A, Friedman A, Nakache R, Cohen $\mathrm{Y}$, et al. Ventilatory and hemodynamic changes during retroperitoneal and transperitoneal laparoscopic nephrectomy: a pro- spective real-time comparison. J Urol 2005;174:1013-1017.

10. Sen O, Umutoglu T, Aydin N, Toptas M, Tutuncu AC, Bakan $\mathrm{M}$. Effects of pressure-controlled and volume-controlled ventilation on respiratory mechanics and systemic stress response during laparoscopic cholecystectomy. Springerplus 2016;5:298.

11. Lessard MR, Guérot E, Lorino H, Lemaire F, Brochard L. Effects of pressure-controlled with different I:E ratios versus volume-controlled ventilation on respiratory mechanics, gas exchange, and hemodynamics in patients with adult respiratory distress syndrome. Anesthesiology 1994;80:983-991.

12. Davis K Jr, Branson RD, Campbell RS, Porembka DT. Comparison of volume control and pressure control ventilation: is flow waveform the difference? J Trauma 1996;41:808-814.

13. Prella M, Feihl F, Domenighetti G. Effects of short-term pressure-controlled ventilation on gas exchange, airway pressures, and gas distribution in patients with acute lung injury/ARDS: comparison with volume-controlled ventilation. Chest 2002;122: 1382-1388.

14. Edibam C, Rutten AJ, Collins DV, Bersten AD. Effect of inspiratory flow pattern and inspiratory to expiratory ratio on nonlinear elastic behavior in patients with acute lung injury. Am J Respir Crit Care Med 2003;167:702-707.

15. McKibben AW, Ravenscraft SA. Pressure-controlled and volume-cycled mechanical ventilation. Clin Chest Med 1996;17: 395-410.

16. Duggan M, Kavanagh BP. Pulmonary atelectasis: a pathogenic perioperative entity. Anesthesiology 2005;102:838-854.

17. Alvarez A, Subirana M, Benito S. Decelerating flow ventilation effects in acute respiratory failure. J Crit Care 1998;13:21-25.

18. Guldager H, Nielsen SL, Carl P, Soerensen MB. A comparison of volume control and pressure-regulated volume control ventilation in acute respiratory failure. Crit Care 1997;1:75-77.

19. Mang H, Kacmarek RM, Ritz R, Wilson RS, Kimball WP. Cardiorespiratory effects of volume- and pressure-controlled ventilation at various $\mathrm{I} / \mathrm{E}$ ratios in an acute lung injury model. Am J Respir Crit Care Med 1995;151:731-736. 